\title{
Ossificação heterotópica em saco herniário incisional
}

\section{Heterotopic ossification in incisional hernia sac}

\author{
Renato Miranda de Melo, TCBC-GO'; Edson Tadeu de Mendonça²; Ernesto Quaresma Mendonça³; Mateus Quaresma Mendonça ${ }^{4}$
}

\author{
R E S U M O
}

\begin{abstract}
O achado de ossificação heterotópica $(\mathrm{OH})$ sobre cicatriz cirúrgica abdominal é um evento raro, mas que soma morbidade ao paciente. Manifesta-se por dor, endurecimento ou desconforto na cicatriz, levando a novas abordagens cirúrgicas. Relatamos um caso de $\mathrm{OH}$ no saco herniário incisional com o objetivo precípuo de chamar a atenção para o potencial "totipotente" do fibroblasto, já que sua íntima relação com a $\mathrm{OH}$ é inegável. A partir dessa prerrogativa, qualquer forma de tratamento das hérnias incisionais deveria associar o reparo tecidual ao uso de prótese (tela), para enriquecê-lo com os fibroblastos e seus fatores de crescimento celular do próprio paciente, todos autólogos e prontos para uso. A tática é oferecer uma abordagem combinada ou mista, com menores chances de recidiva na correção dessas afecções.
\end{abstract}

Descritores: Ossificação heterotópica. Cicatriz. Osteogênese. Morbidade. Hérnia ventral.

\section{INTRODUÇÃO}

O ssificação heterotópica $(\mathrm{OH})$ é a formação de tecido ósseo fora do sistema esquelético, que pode ocorrer em todos os tipos de tecidos moles ${ }^{1-3}$. Também chamada de miosite ossificante, é uma doença relativamente comum após operações ortopédicas, sobretudo as artroplastias, embora a patogênese exata da doença ainda não tenha sido esclarecida ${ }^{3}$. Na cirurgia abdominal é considerada uma complicação rara, ocorrendo principalmente na linha média. Pode eventualmente causar dor ou desconforto e o tratamento consiste na ressecção cirúrgica completa do tecido ósseo neoformado. Apresentamos um caso de $\mathrm{OH}$ abdominal, no saco herniário de paciente com hérnia incisional mediana e suas implicações cirúrgicas.

\section{Técnica}

Paciente masculino, 35 anos de idade, apresentou-se com hérnia incisional mediana xifopúbica, volumosa e dor no epigástrio (ângulo superior da hérnia). Dez meses antes, foi submetido à nefrectomia direita e controle de dano em lesão hepática, decorrente de trauma abdominal contuso. Foi reoperado dois dias depois para retirada de compressas e confecção de peritoniostomia com tela de polipropileno revestida. Permaneceu internado por 45 dias com sepse abdominal grave. Foi submetido ao fechamento da peritoniostomia, mediante aproximação apenas da pele, antes de receber a alta.
Ao exame, apresentava hérnia incisional mediana xifopúbica volumosa e algo doloroso na sua porção cranial. Palpava-se, abaixo do rebordo costal esquerdo, massa irregular e endurecida. A suspeita era de que um fragmento da tela de polipropileno, utilizada por ocasião da peritoniostomia, justificasse as queixas do paciente.

Procedeu-se à abordagem do saco herniário, que revelou extenso tecido ósseo em formação nos ângulos da cicatriz, sobretudo no superior (Figuras 1 e 2). Ressecou-se todo o tecido ósseo neoformado, que estava fortemente aderido às bordas do anel herniário, com auxílio do bisturi elétrico (Figuras 3 e 4 ). A peça cirúrgica consistia de dois fragmentos ósseos, sendo o inferior de aproximadamente $3 \mathrm{~cm}$ em seu maior eixo, e o superior de $11 \mathrm{~cm}$ (Figura 5). A hérnia incisional foi corrigida pela técnica de Lázaro da Silva ${ }^{4}$ (transposição peritônio-aponeurótica longitudinal bilateral - TRANSPALB) e o paciente evoluiu sem outras complicações.

\section{DISCUSSÃO}

A ossificação heterotópica $(\mathrm{OH})$ representa um subtipo de miosite ossificante traumática, na qual elementos ósseos e cartilaginosos são formados dentro de tecidos moles, onde normalmente não há esse tipo de formação. Ocorre, por exemplo, na pele, em cicatrizes e na gordura subcutânea ${ }^{1-3,5}$. O mais comum é surgir após traumatismo músculo-esquelético ou do sistema nervoso central (lesão

Trabalho realizado no Hospital e Maternidade Jardim América e no Departamento de Cirurgia da Faculdade de Medicina da Universidade Federal de Goiás, Goiânia, GO, Brasil.

1. Cirurgião Geral do Hospital e Maternidade Jardim América-GO-BR; 2. Médico Residente de Cirurgia Geral do Hospital das Clínicas da FM-USPSP-BR; 3. Professor Adjunto do Departamento de Cirurgia da FM-UFG e da PUC-Goiás-BR; 4. Acadêmico de Medicina da FM-UF-GO-BR. 


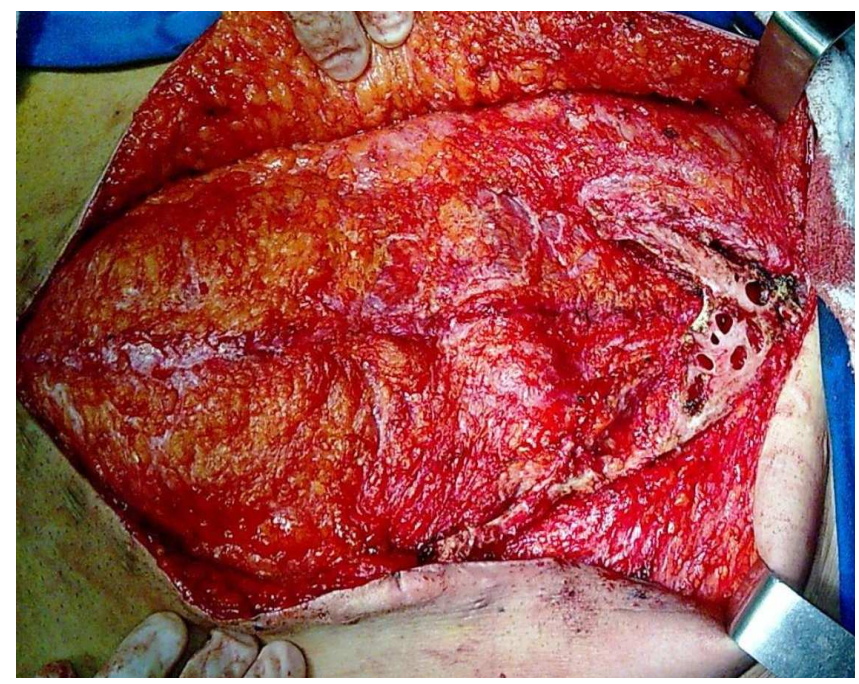

Figura 1 - Achado intraoperatório da ossificação heterotópica.

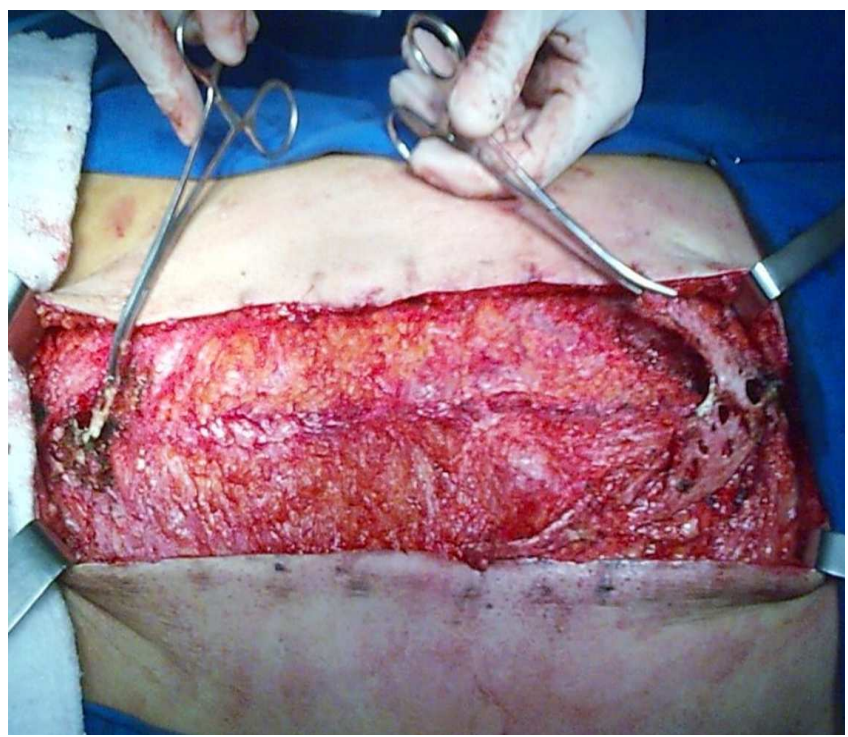

Figura 2 - Demonstração de ossificação em ambos os ângulos da ferida operatória.

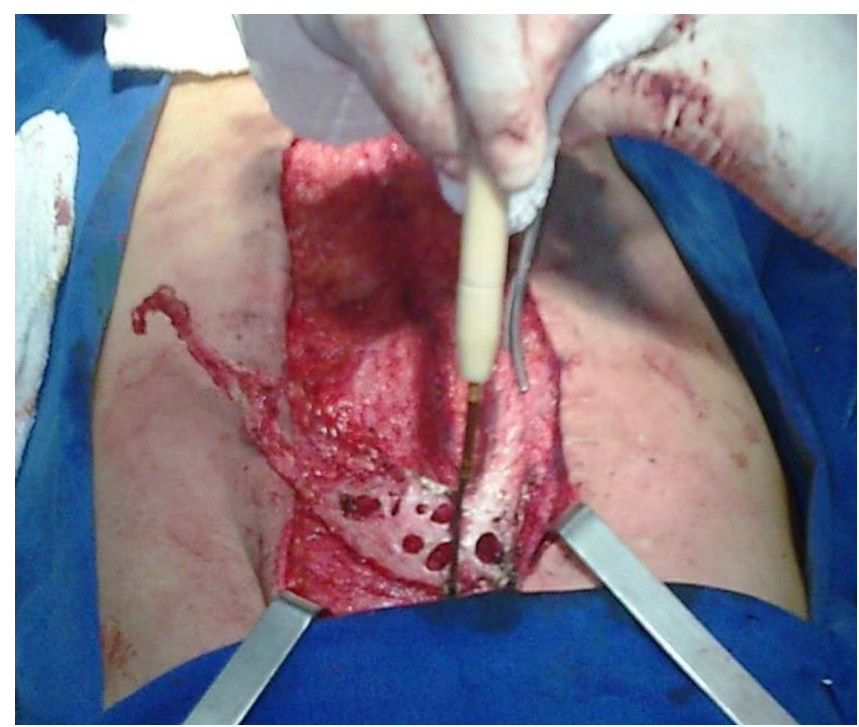

Figura 3 - Descolamento do tecido com auxílio do bisturi elétrico.

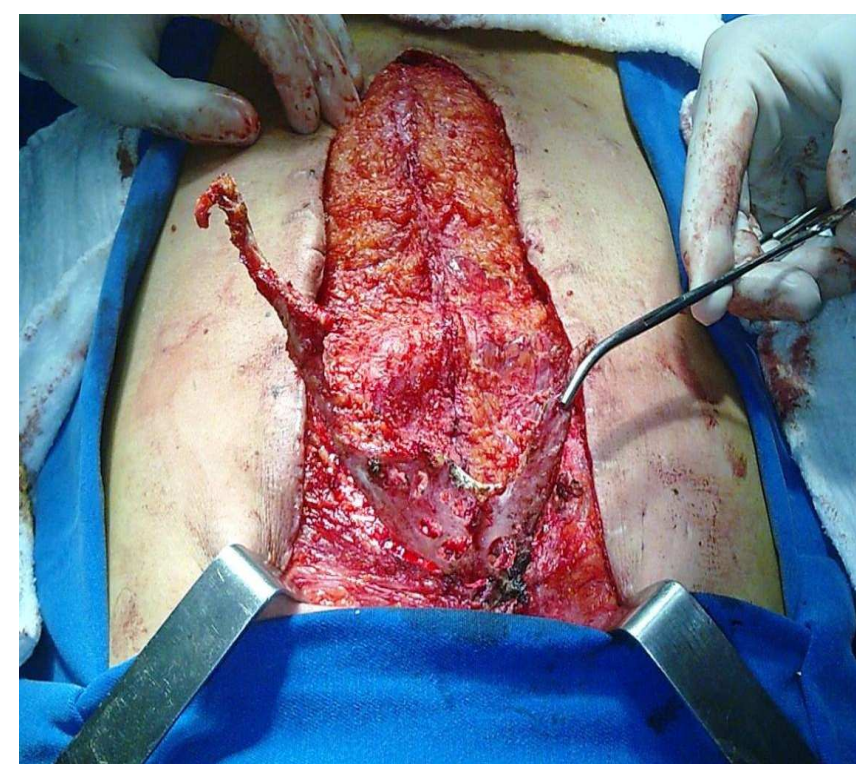

Figura 4

Tecido ossificado após o seu descolamento das bordas do anel herniário.

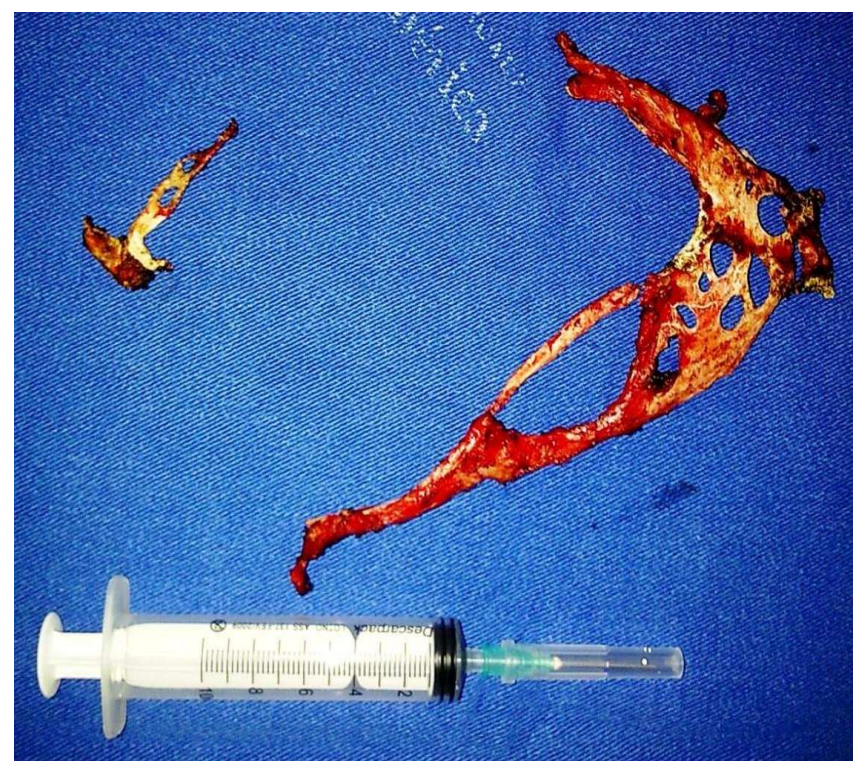

Figura 5 - Aspecto pós-operatório dos fragmentos ósseos.

medular). Observa-se que pacientes submetidos à operações ortopédicas, tais como artroplastias do ombro ou do quadril, ou que apresentaram paraplegia após lesão medular, têm maior risco para desenvolverem a $\mathrm{OH}$. A miosite ossificante traumática tem sido repetidamente relatada na literatura, em geral depois de contusão muscular causada pela prática de esportes ${ }^{6}$.

Embora a etiologia da $\mathrm{OH}$ seja incerta, é inquestionável sua íntima relação com as ações do fibroblasto. Quando um tecido é lesado, os fibroblastos mais próximos migram para esse tecido, proliferam e produzem grandes quantidades de matriz colágena, contribuindo para isolar e reparar aquele dano. O fibroblasto também parece ser a mais versátil célula do tecido conjuntivo, mostrando uma notável capacidade de se diferenciar em outros ele- 
mentos, tais como o osteoblasto, o condroblasto, o adipócito e a célula muscular lisa ${ }^{7}$. Algumas teorias tentam explicar essa formação óssea anômala ${ }^{1,2}$

Na primeira, as partículas do periósteo ou do pericôndrio, seja do processo xifóide e/ou da sínfise púbica, são inoculadas na ferida, durante a operação primária, e, assim, levam à neoformação óssea. Esta teoria não é suficiente para explicar a OH, quando não há estreita relação anatômica (contiguidade) com o tecido ósseo primário.

A segunda teoria afirma que a formação de osso heterotópico é o resultado de células mesenquimais pluripotentes imaturas, que se diferenciam em osteoblastos ou condroblastos, em resposta à lesão próxima. Esta seria a explicação mais lógica, para os raros casos de formação óssea intra-abdominal descritos na literatura (miosite ossificante intra-abdominal ou ossificação heterotópica mesentérica) ${ }^{8}$. No presente caso, esta teoria explicaria, de modo satisfatório, a $\mathrm{OH}$ no saco herniário incisional mediano, uma vez que ele é constituído, eminentemente, de tecido conjuntivo cicatricial (fibroblastos, fibras e matriz extracelular).

A terceira teoria é a da tensão excessiva na linha de sutura, que poderia levar à implantação intramuscular de partículas arrancadas dos locais de inserção no osso.

Em geral, a formação óssea ectópica em cicatriz mediana ocorre dentro de poucos meses e, quase sempre, no primeiro ano depois da operação. Nesse paciente, ela foi observada dentro de dez meses após as várias abordagens cirúrgicas a que foi submetido. A ossificação de cicatriz cirúrgica tem sido observada apenas em incisões longitudinais, e, até agora, não foi descrita em incisões transversais ${ }^{1,2,5}$. Também não foram relatados casos dessa afecção no saco herniário, seja incisional, seja de outro tipo ou localização.

Embora rara, a $\mathrm{OH}$ em cicatrizes de laparotomias medianas pode causar dor ou desconforto local. O tratamento consiste na excisão completa do tecido neoformado, com novo fechamento da ferida. Algumas formas adicio- nais de tratamento como, por exemplo, a terapia com radiação, são utilizadas como forma de prevenção e de tratamento da $\mathrm{OH}$ após cirurgia ortopédica, mas ainda são controversas, principalmente na cirurgia abdominal ${ }^{3}$.

$\mathrm{Na}$ literatura, existem três relatos de $\mathrm{OH}$ recorrente em cicatrizes cirúrgicas ${ }^{5}$. No presente caso, nenhuma recorrência foi observada seis meses após a excisão. Refere-se que a formação óssea ectópica recorrente deve ser tratada mediante nova excisão e radioterapia pós-operatória. Eventualmente, anti-inflamatórios não esteroidais podem ser usados para prevenir a formação de osso heterotópico recorrente ${ }^{1,5}$.

É importante distinguir esta entidade, que é de natureza benigna, de outras complicações pós-operatórias locais (infecção do sítio cirúrgico e corpos estranhos, entre outras) e também da neoplasia primária ou metastática intraincisional. Para isso, pode-se utilizar exames de imagem, como tomografia computadorizada, ressonância nuclear magnética e estudos com medicina nuclear envolvendo radiofármacos ${ }^{2}$. No caso, a hipótese levantada foi de que poderia existir um fragmento de tela de polipropileno deixado por ocasião da peritoniostomia. A exclusão da hipótese de tecido ósseo neoplásico, por meio do exame anatomopatológico, é também vital. Histologicamente, a $\mathrm{OH}$ é composta de osso maduro com medula e elementos cartilaginosos, rodeados por tecido fibroso. Esse foi o padrão encontrado no caso em questão.

Talvez o principal desdobramento a ser considerado, neste relato, é chamar a atenção do cirurgião para o potencial "pluripotente" do fibroblasto, cujo papel nesta afecção não foi elucidado completamente, mas sabe-se que ele está presente durante a cicatrização e também no desenvolvimento da $\mathrm{OH}$. Isso reitera a importância de se utilizarem os próprios tecidos do paciente, ricos nesses elementos celulares e em seus fatores de crescimento, nas herniorrafias de qualquer tipo ou localização, ainda que suplementando-as com prótese (tela). Além disso, o cirurgião deve se esmerar na técnica operatória empregada, para evitar o desencadeamento da ossificação heterotópica.

\title{
A B S T R A C T
}

\begin{abstract}
The heterotopic ossification (HO) on abdominal scars is a rare but very unconfortable finding. It causes pain, induration and discomfort in the scar, leading patients to undergo reoperation. This report aims to describe a case of HO, and especially to call attention of surgeons to fibroblast transforming potential, once its close relationship with $\mathrm{HO}$ is undeniable. Therefore the surgeon should endeavor all atempts on good surgical practice to avoid HO occurrence. He should also associate pure tissue repair techniques to prosthetic management of incisional hernias, in the hope that patient's fibroblast grow factors can be offered to the wound healing as a biologically reinforcement of the repair.
\end{abstract}

Kew words: Ossification, heterotopic. Cicatrix. Osteogenesis. Morbidity. Hernia, ventral.

\section{REFERENCIAS}

1. Degirmenci B, Acar M, Albayrak A, Haktanir A, Cel AY, Dülek ON. Heterotopic bone formation in upper midline abdominal incision. Turk J Med Sci. 2005:35:189-91.
2. Jacobs JE, Birnbaum BA, Siegelman ES. Heterotopic ossification of midline abdominal incisions: CT and MR imaging findings. AJR Am J Roentgenol. 1996;166(3):579-84.

3. Koolen PG, Schreinemacher MH, Peppelenbosch AG. Heterotopic ossifications in midline abdominal scars: a critical review of the literature. Eur J Vasc Endovasc Surg. 2010;40(2):155-9. 
4. Melo RM. Reconstruindo a parede abdominal: o advento de uma técnica. Rev Col Bras Cir. 2010; 37(6):450-56

5. Sanders RL. Bone formation in upper abdominal scars. Ann Surg. 1955; 141(5):621-6.

6. King JB. Post-traumatic ectopic calcification in the muscles of athletes: a review. Br J Sports Med. 1998;32(4):287-90.

7. Alberts B, Johnson A, Lewis J, Raff M, Roberts K, Walter P. Molecular biology of the cell, $4^{\text {nd }}$ ed. New York: Garland Science; 2002. Fibroblasts and their transformations: the connective-tissue cell family. Disponível em: http://www.ncbi.nlm.nih.gov/books/ NBK28373/

8. Athanazio DA, Carvalho ALL, Silva NO, Athanazio PRF. Heterotopic intraabdominal ossification: report of a case and review of the literature. J Bras Patol Med Lab. 2009;45(2):125-30.
Recebido em 03/04/2011

Aceito para publicação em 05/07/2011

Conflito de interesse: nenhum

Fonte de financiamento: nenhuma

\section{Como citar este artigo:}

Mendonça MQ, Mendonça ET, Mendonça EQ, Melo RM. Ossificação heterotópica em saco herniário incisional. Rev Col Bras Cir. [periódico na Internet] 2012; 39(2). Disponível em URL: http://www.scielo.br/rcbc

Endereço para correspondência:

Mateus Quaresma Mendonça

E-mail: mateusqm@hotmail.com 